\title{
The Influence of Past Racism on Criminal Injustice: A Review of The New Jim Crow and The Condemnation of Blackness
}

\section{Jelani Jefferson Exum}
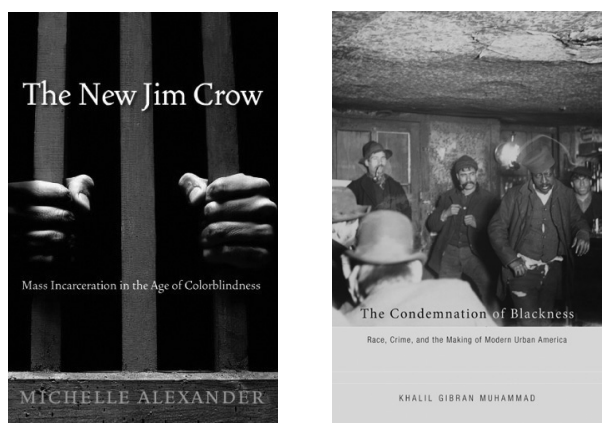

THE NEW JIM CROW: Mass Incarceration in the Age of Colorblindness. By Michelle Alexander. New York: The New Press. 2010. THE CONDEMNATION OF BLACKNESS: Race, Crime, and the Making of Modern Urban America. By Khalil Gibran Muhammad. Cambridge: Harvard University Press. 2010.

There are books that, on their own, are informative and moving. But, oftentimes, reading books together-one right after the other-compounds each works' transformative power. Michelle Alexander's much-needed report (calling it simply a book hardly does it justice), The New Jim Crow: Mass Incarceration in the Age of Colorblindness, can certainly stand on its own as an important statement about the current use of mass incarceration to maintain a racial caste system in the United States. The same strength can be found in The Condemnation 
of Blackness: Race, Crime, and the Making of Modern Urban America, Khalil Gibran Muhammad's account of the connection of blackness to criminality in this country. Each book, on its own, gives readers a greater understanding of the racism within the criminal justice system. However, reading them jointly paints a disturbing picture of the past and present use of incarceration and crime rhetoric in America and leaves one with an overwhelming sense of injustice and the data to know that the injustice is real.

I was asked to review both books, and so I read them back to back-The New Jim Crow first, and The Condemnation of Blackness second. I did not think much about the order in which I read the books, and I suppose that it may have made more sense for me to have read them in the reverse of the order that I chose. The Condemnation of Blackness makes the case for the idea of black criminality being created during the making of urban America. It focuses on the history of American cities and the treatment and view of blacks in those cities. While The New Jim Crow looks to history as well, its purpose is to liken the country's current system of mass incarceration to the Jim Crow caste system of old. Therefore, in a chronological sense, The Condemnation of Blackness sets the historical stage for the discussion that takes place in The New Jim Crow. However, my unintentional mis-ordering of the books (I simply picked up one first and began reading it) made the reading less of a history lesson, and more of an insight into the unsettling character of the black face of crime in America. Starting this journey with The New Jim Crow makes a reader deeply question whether the high rates of incarceration in the United States could indeed be a determined effort to maintain blacks as an underclass. Following that reading with The Condemnation of Blackness, opens one's eyes to the persistent effort throughout America's history to attach criminality to blackness, making the claim made in The New Jim Crow seem, not only plausible, but hard to doubt. In concert, the two books expose the enormously disquieting power of the criminal justice system over the past, present, and future of an entire group of Americans.

In The New Jim Crow, Michelle Alexander makes the claim that "[w]e have not ended racial caste in America; we have merely redesigned it" using the criminal justice system and colorblind rhetoric (2). In building her argument, she begins with the lineage of Jarvious Cotton, a black man who cannot vote due to his status as a felon on parole $\left(\mathrm{NJC}^{1} 1\right)$. What is interesting about Cotton's history is that his great-great-grandfather was a slave who could not vote; his great-grandfather was killed by the Ku Klux Klan for trying to vote; Klan intimidation stopped his grandfather from attempting to vote; and poll taxes and literacy tests prohibited his father from voting ( NJC 1). Alexander explains Cotton's disenfranchised pedigree this way: "In each generation, new tactics have been used for achieving the same goals - goals shared by the Founding Fathers. Denying African Americans citizenship was deemed essential to the formation of the original union" (NJC 1). Alexander then goes on to explain how incarceration and its collateral consequences (such as bars to employment, housing, education, 
public benefits, and jury service) are used to impose what she terms "legalized discrimination" on African Americans (NJC 1-2). The result, according to Alexander, is a population of black men who face similar barriers and deprivation of rights as did blacks during the Jim Crow era. Hence, mass incarceration has become the new Jim Crow.

In making the case that mass incarceration is Jim Crow revisited, The New Jim Crow quickly moves through a history of racial caste systems from slavery to Jim Crow (NJC 20-40). While readers may already know much about slavery and the Jim Crow system of Reconstruction, Alexander illuminates this history by explaining that it was during these racially combative periods of American history that the stage was set for maintaining a black underclass through the use of race-neutral language. Slavery was a clear racial caste system in which laws - including the U.S. Constitution - were used to ensure that blacks would live and be treated as a distinct group, best described as chattel. When slavery died, the notions of white supremacy that it helped to breed lived on through Jim Crow laws and practices. The racial division that characterized the Jim Crow era required "[f]aith in the belief that people of the African race were bestial, that whites were inherently superior, and that slavery was, in fact, for black's own good" (NJC 26). So, with slavery's demise, a new form of control of blacks was needed in order to maintain the racial order for which white supremacy called. In addition to the de jure and de facto segregation prevalent at this time, Alexander reveals that it was during the Reconstruction period that America experienced its first prison boom, and "the prisoners were disproportionately black" (NJC 32). But, with the legal and social victories of the Civil Rights Movement, Jim Crow, too, would eventually die. As Alexander explains, "Jim Crow eventually replaced slavery, but now it too had died, and it was unclear what might take its place. Barred by law from invoking race explicitly, those committed to racial hierarchy were forced to search for new means of achieving their goals according to the new rules of American democracy" (NJC 40). So, how were the racial disparities in incarceration maintained? Welcome mass incarceration.

Alexander introduces the birth of mass incarceration in the first chapter of The New Jim Crow which is full of what I thought was the most interesting information in the entire book. This is not to say that the other five chapters were not illuminating as well. However, Alexander's explanation of how the mass incarceration developed from a contrived racial discourse about law and order was truly captivating. The author describes how the same separatist sentiments that fueled the Jim Crow system were used to appeal to poor and working class whites who were still reeling from the triumphs of the Civil Rights fight. This "law and order rhetoric" was the foundation for the "Southern Strategy," a political effort by the Republican Party to bring southern white voters into their camp (NJC 4243). The enthralling aspect of Alexander's account of the Southern Strategy has much to do with how she craftily weaves powerful quotes into her telling of the story. For example, she incorporates the following words of one of Pres. Richard Nixon's key advisers on Nixon's strategy: "He [President Nixon] emphasized 
that you have to face the fact that the whole problem is really the blacks. The key is to devise a system that recognizes this while not appearing to" (NJC 43-44). Alexander links this shockingly blatant use of racial polarization to the eventual association of blacks with crime. The steps proceed as follows: Republican campaigns in the late 1960s and early 1970s curried favor with anti-black voters by appealing to their belief that blacks were the root of societal problems; poverty and other social ailments then become divorced from government deficiencies and tied to the culture of the poor; the culture of the poor, which included criminal behavior is no longer associated with responses to poverty, but instead seen as the pathology of the black subculture (the "'welfare cheats' and their dangerous offspring")- after all, this all started with the idea that blacks were the root of societal problems anyway (NJC 44-45). The explanation of this development moves along so seamlessly that it hardly seems like a surprise when the author reveals that, "By 1968, 81 percent of those responding to the Gallup Poll agreed with the statement that 'law and order has broken down in this country,' and the majority blamed 'Negroes who start riots' and 'Communists"' (NJC 45). And just as the reader is riding this wave of rhetoric, Alexander slams us against the shore with a disturbingly blunt statement attributed to Pres. Nixon as he viewed one of his own campaign ads that used the law and order approach: "[The ad] hits it right on the nose. It's all about those damn Negro-Puerto Rican groups out there" (NJC 46). And, the real point that Alexander is making hits with blunt force- this was all purposeful.

The rest of Chapter 1 tracks the move from the anti-black law and order language to mass incarceration through the similar campaign approach of Pres. Ronald Reagan denouncing " "welfare queens' and criminal 'predators"” (NJC 47). But, it was in 1982 when, during his presidency, Reagan set the rhetoric into action by declaring the infamous War on Drugs despite the fact that, at the time, the American public did not see drugs as a major issue (NJC 49). Alexander explains Pres. Reagan's motivations this way: "This fact [that drugs were not the nation's major priority] was no deterrent to Reagan, for the drug war from the outset had little to do with public concern about drugs and much to do with public concern about race. By waging a war on drug users and dealers, Reagan made good on his promise to crack down on the racially defined 'others' - the undeserving" (NJC 49). And, with that, the mass conduit to prison for blacks was created.

The New Jim Crow goes on in Chapter 1 to explain in depth how the War on Drugs combined with crack cocaine violently hitting the streets of American inner cities mixed with the Anti-Drug Abuse Act of 1986 and the rise in mandatory minimum drug sentencing in 1988 , gave a race-neutral justification for whites to rely on in "express[ing] their hostility toward blacks and black progress, without being exposed to the charge of racism" (NJC 53). Alexander argues that this new tool of color-blind justice that allowed for the disparate incarceration of blacks was used by Pres. George Bush Sr., and even by Pres. Bill Clinton who escalated the War on Drugs (NJC 53-55). The Justice Policy Institute reports 
that the Clinton presidency "resulted in the largest increases in federal and state prison inmates of any president in American history" (NJC 55). Alexander takes that statement and explains that Clinton "more than any other president - created the racial undercaste" by using his tough on crime approach to create barriers to welfare (NJC 56). As the author sets forth, by the 1990s the War on Drugs and all of its collateral consequences were cloaked in race-neutral, colorblind terms. However, the casualties of the War could certainly be understood in racial terms. Alexander reveals that "Ninety percent of those admitted to prison for drug offenses in many states were black or Latino" (NJC 57). She ends the chapter simply, yet poignantly, with these words: "The New Jim Crow was born" (NJC 57).

The rest of The New Jim Crow builds Michelle Alexander's case for likening mass incarceration to the Jim Crow racial caste system. She gives data on the extraordinary number of drug offenders in prisons across the nation and explains how the Supreme Court and federal incentives have made filling prisons with drug offenders an easy and profitable task for law enforcement (NJC Chapter 2, "The Lockdown," 58-94). Alexander also tackles the role that discretion in the criminal justice process has played in creating racial disparities in the prison population, with blacks getting the brunt of the prison burden (NJC Chapter 3, "The Color of Justice," 95-136). The book goes on to reveal the host of collateral consequences to this rampant use of incarceration of blacks-from the well-known legal consequences on housing, employment, and voting, to the less obvious consequences such as difficulties in paying pre- and post-conviction fees, shame and stigma, and the creation of a media-embraced black gangster culture (NJC Chapter 4, "The Cruel Hand," 137-172). All of these supporting points give the reader a reason to buy into the case made in Chapter 5, "The New Jim Crow" (NJC 173-208). In Chapter 5, Alexander starts by addressing the reality of missing black men, lulling the reader in with a familiar question, "Where have all the black men gone?" (NJC 174) She blames the void on the War on Drugs, insisting, "Hundreds of thousands of black men are unable to be good fathers for their children, not because of a lack of commitment or desire but because they are warehoused in prisons, locked in cages. They did not walk out on their families voluntarily; they were taken away in handcuffs, often due to a massive federal program known as the War on Drugs" (NJC 175). It is in Chapter 5 where Alexander weaves the devastation of mass incarceration on the black community together with a misunderstanding of racism by a society that fancies itself colorblind and its laws and policies race-neutral. Alexander states, "The widespread and mistaken belief that racial animus is necessary for the creation and maintenance of racialized systems of social control is the most important reason that we, as a nation, have remained in deep denial" (NJC 178). Alexander proceeds to connect the information presented in earlier chapters to her claim that mass incarceration is the new Jim Crow. She breaks down "how the system of mass incarceration works to trap African Americans in a virtual (and literal) cage" by describing three stages: the roundup; the period of formal 
control; and the period of invisible punishment (NJC 180-182). By revealing the pervasiveness of this trap as a "comprehensive system of control over [a] racial [...] defined population" (NJC 183) and moving on to discuss the similarities between this trap and the Jim Crow system, Michelle Alexander solidly makes her point that: "It is fair to say that we have witnessed an evolution in the United States from a racial caste system based entirely on exploitation (slavery), to one based largely on subordination (Jim Crow), to one defined by marginalization (mass incarceration)" (NJC 207).

Of course, no book about crime and race can be without controversy, and certainly not one that likens today's criminal justice system with the purposeful and undoubtedly racist system of Jim Crow. Though Alexander's arguments flow easily in The New Jim Crow, there are several points at which a reader could disagree. Alexander herself goes through the limitations of the Jim Crow analogy (NJC 195 -208). She admits that mass incarceration may not be built upon "overt racial hostility" and that there are whites who have fallen victim to the War on Drugs and blacks who support policies that are tough on crime (NJC 197-208). A reader could pick any of these limitations as a reason to part ways with the author on her comparison. However, whatever questions or disagreements a reader might have when she reaches the last page of the book, the scholarly value is unmistakable-Michelle Alexander's The New Jim Crow compels its readers to face the ravaging effects that mass incarceration and the colorblind laws that support it have had on the black community. Once that curtain has been opened and the consequences of the system exposed, likening mass incarceration to Jim Crow can be accepted by readers as a powerful push needed to inspire change. The New Jim Crow does just that.

Khalil Gibran Muhammad's The Condemnation of Blackness approaches the issue of race and crime from a different perspective than does The New Jim Crow, by focusing on the development of "the idea of black criminality in the making of urban America" rather than on the current form that such an idea takes in mass incarceration $\left(\mathrm{COB}^{2} 1\right)$. Muhammad's book is a denser read, full of illuminating quotes and statistics to support his ultimate assertion that "[v]iolent crime rates in the nation's biggest cities are generally understood as a reflection of the presence and behavior of the black men, women, and children who live there" (COB 1). From the start, The Condemnation of Blackness presents an easier position for a reader to accept than does The New Jim Crow. Much of this is due to Muhammad's constant and repeated reference to the work and beliefs of sociologists, psychologists, criminologists, and others who were the relevant thinkers of their time throughout the book. The author begins this tactic in the book's Introduction in which he refers to the work of W.E.B. Du Bois, Orlando Patterson, Jeffrey Alder, Charles Henderson, and a host of others, that all support the view that crime and blackness became synonymous over time though crime among whites has historically been explained using race-neutral reasons. (COB Introduction, "The Mismeasure of Crime," 1-14). For instance, as early as the second page of the Introduction, Muhammad invokes the 1928 words of 
Thorsten Sellin whom he describes as "one of the nation's most respected white sociologists" who attested, "We are prone to judge ourselves by our best traits and strangers by their worst. In the case of the Negro, stranger in our midst, all beliefs by him prejudicial to him aid in intensifying the feeling of racial antipathy engendered by his color and his social status. The colored criminal does not as a rule enjoy the racial anonymity which cloaks the offenses of individuals of the white race" (COB 2). Once reading the Introduction, a reader will hardly need convincing that Sellin's words and Muhammad's position are accurate. The rest of the book, then, is less about proving a point, and more about giving the reader a method of understanding how this condemnation of blackness came to be.

Muhammad begins this "unsettling coming of age story" (COB 1) by discussing the post-Civil War need to deal with the "Negro Problem" posed by black freedom (COB Chapter 1, "Saving the Nation: The Racial Data Revolution and the Negro Problem," 15-34). It was during this post-emancipation era that white thinkers began pondering the nature of black humanity. "What grade of humankind were these Africans in America? What quality of citizenship did they truly deserve? What manner of coexistence should be tolerated?" (COB 19). All eyes were on blacks to see how they would fare as free people and what their successes and failures as a group meant about who they were. As Muhammad explains, "Statistical data on the absolute and relative growth of the black prison population in the 1890 census, for example, would now be analyzed and interpreted as definitive proof of blacks' true criminal nature" (COB 33-34). If the reader, as I had, began this journey with Michelle Alexander's The New Jim Crow, then Muhammad's next sentence would be especially illuminating. Muhammad writes, "Such empirical evidence could then justify a range of discriminatory laws, first targeting blacks, then punishing them more harshly than whites" (COB 34). With those few words, the link between the first Jim Crow and the "new" Jim Crow becomes even more evident. It was at this point that I was pleased to be reading The Condemnation of Blackness after The New Jim Crow, though the reverse order initially seemed the more prudent approach. What would have already been an extremely instructive and penetrating read, The Condemnation of Blackness became, for me, an elucidation of The New Jim Crow as another fascinating commentary on America's criminal justice system. In turn, having just read The New Jim Crow, I had a better appreciation for the bearing that the history presented in The Condemnation of Blackness had on the current attitudes fueling this country's current dependence upon mass incarceration.

Once the scene has been set for using crime statistics as a way of defining black humanity, The Condemnation of Blackness, goes on to develop how just being black came to mean being criminally inclined. In Chapter 2, "Writing Crime Into Race: Racial Criminalization and the Dawn of Justice," Muhammad describes the debate among statisticians and sociologists about how to understand crime among blacks in the 1890s. The dispute was between those like Frederick L. Hoffman who, in his 1896 Race Traits and Tendencies of the American Negro, saw "[c]rime, pauperism, and sexuality immorality" as "ten- 
dencies of the colored race" that needed further study (COB 35), and those like prison doctor M. V. Ball who maintained that governments should " "[m]ake the conditions favorable for the negro from childhood up, and then first can we say that' blacks are more disease prone" and that "The criminal nature of the negro must be viewed in the same light" (COB 43). As views like Hoffman's began to win out in popularity and social conditions were dismissed as contributors to crime among blacks, Muhammad notes that "Hoffman's persistent efforts to render racism invisible were paying off" (COB 56). As I read this, it dawned on me that Khalil Gibran Muhammad was describing the first steps toward the type of colorblindness that Michelle Alexander presented as the powerful mode of thinking used to hide the racism present in the mass incarceration system. Crime statistics continued to be interpreted in such a way that black criminality became an expected phenomenon, thus justifying any laws necessary to control it. To make his point that this discourse about crime among blacks was developing in a way that condemned blackness, Muhammad also tracks the trend of addressing white crime at this time. As he explains it, "White criminality was society's problem, but black criminality was black people's problem" (COB 76).

Though reading criminal nature into blackness is problematic enough, The Condemnation of Blackness presents an even more nuanced view of the issue by presenting the manner in which liberal thought also contributed to the notion of black as criminal. In the book's third chapter, "Incriminating Culture: The Limits of Racial Liberalism In The Progressive Era" (COB Chapter 3, 88-145), Muhammad identifies two pivotal changes in black crime discourse that took place during the Progressive Era. He describes them as follows: "The first was the appeal for 'remedial measures' in solving the Negro Problem, including expanded economic opportunities, education, social work, and crime prevention. The second was the rejection of biological determinism, including redefining racial traits as cultural traits, a paradigmatic shift in the science of race that placed African Americans once and for all within the pale of civilization, at least in the minds of most liberal social scientists" (COB 90). With this intriguing description of the Progressive Era, Muhammad strips away the seemingly beneficial social welfare programs and exposes a view of race that was just as critical to solidifying the popular connection between blacks and crime- the turn to culture. While initially it may seem to a reader that the move away from seeing criminal nature as a biologically determined black trait would be a positive step, Muhammad explains the danger of exchanging biology as the cause for culture. He quotes sociologist Tukufu Zuberi who argued that this "was a move from one type of essentialist perspective, the biological evolutionary, to another type of essentialist perspective, the cultural. This shift witnessed the birth of assimilation and a focus on unproductive behavior of the unassimilated as a dominant perspective - in a word, a return to viewing the 'Negro as a [peculiar] problem"” (COB 100). Muhammad explains it further with his own analysis: "The writing of crime into culture, then, became a counter-discourse that was deeply flawed, not because it inherently examined the crimes and immorality 
of individual blacks but because it emphasized the cultural distinctiveness of black thieves, rapists, and murderers" (COB 101). Though throughout the book Muhammad acknowledges the work of those struggling to disentangle crime and race, the reader gets the disheartening sense at this point that blackness had been tied to criminality for so long and with such strength that even the "friends of the Negro" simply found a new way to reinforce the connection (COB 125). W.E.B. Du Bois spoke it plainly when he asserted "that it was blackness that was condemned, and not the crime" (COB 141).

With the stage set for the reader to understand the pervasiveness of the perception that crime and blackness went hand in hand, the rest of The Condemnation of Blackness proceeds to discuss the effects of that belief on attitudes toward crime prevention (COB Chapter 4, "Preventing Crime: White and Black Reformers in Philadelphia," 146-191) and law enforcement tactics (COB Chapter 5, "Fighting Crime: Politics and Prejudice in the City of Brotherly Love," 192-225). The attitudes and tactics described in the book are both precursors and responses to the growth of black urban centers in the North. For example, Muhammad explains that " $[t]$ he onset of wartime migration of African Americans to Philadelphia from southern farms and cities generated new discussions of black crime. In part, this reaction was a simple calculation based on pure numbers: the more blacks who came to the city, the more crime that would follow. The link between black migration and crime had been firmly established at the end of the nineteenth century" (COB 206). This development leads to a quite interesting and crafty scheme developed by "white vice owners and corrupt politicians to hide their illegal activities under a cover of blackness" by encouraging city officials to be more tolerant of crime in black communities (COB 226). This tactic of providing less protection in black neighborhoods, thus creating crime ridden areas, is discussed in Chapter 6 of the book (COB Chapter 6, "Policing Racism: Jim Crow Justice in the Urban North," 226-268). For those who read The New Jim Crow before turning to The Condemnation of Blackness, this chapter on the purposeful facilitation of crime in black neighborhoods will sharpen their understanding of Michelle Alexander's premise that the U.S. system of mass incarceration has continued a racial caste system. If black neighborhoods became known as usable as a cover for crime, it is easy to see that they would become synonymous with crime, and once law enforcement efforts did begin to focus on those communities, certainly residents of black neighborhoods would be the ones funneled into the prison system. In this way, both books, though each powerful on its own, speak to one another in a manner that enhances and exhibits the scholarly quality of each.

Despite their dismaying subject matter, both The Condemnation of Blackness: Race, Crime, and the Making of Modern Urban America and The New Jim Crow: Mass Incarceration in the Age of Colorblindness end on hopeful notes by putting power into the hands of the readers. In The Condemnation of Blackness, Khalil Gibran Muhammad tells us that "[b]y illuminating the idea of black criminality in the making of modern urban America, it becomes clear 
that there are options in how we choose to use and interpret crime statistics. They may tell us something about the world we live in and about the people we label 'criminals.' But they cannot tell us everything" (COB 277). Because measuring crime has both limitations and power, Muhammad explains that "[t]he choice about which narratives we attach to the data in the future $[\ldots]$ is ours to make" (COB 277). He concludes with a nod to past social justice advocates for whom he says, "[s]ympathy and faith in humanity were chosen over scorn and contempt" (COB 277). Michelle Alexander ends The New Jim Crow by invoking humanity as well when she warns that "if the movement that emerges to end mass incarceration does not meaningfully address the racial divisions and resentments that gave rise to mass incarceration, and if it fails to cultivate and ethic of genuine care, compassion, and concern for every human being —of every class, race, and nationality — within our nation's borders [...], the collapse of mass incarceration will not mean the death of racial caste in America" (NJC 245). She urges for those concerned to "lay down our racial bribe, join hands with people of all colors who are not content to wait for change to trickle down, and say to those who would stand in our way: Accept all of us or none" (NJC 245). These inspiring words from both authors make it clear that there is work to be done. Both books also leave the reader to grind out the details of how to undue decades of deliberate and often carefully orchestrated campaigns to condemn blackness such that a racial undercaste would be possible. And, not only must readers figure out a plan of action, we must do so under the weighty cloak of colorblind rhetoric that allows the condemned undercaste to exist as a result of today's race-neutral laws. A daunting task, yet one that readers will at least be moved to contemplate and certainly armed to advocate for after reading these deservedly celebrated texts.

\section{Notes}

1. Pages from The New Jim Crow are identified as "NJC."

2. Pages from The Condemnation of Blackness are identified as "COB." 